\title{
Overeenstemming tussen antropometrische methoden voor de bepaling van de gewichtsstatus
}

\author{
I. Everink ${ }^{1}$, M.A. Maaskant ${ }^{2}$, A.G.M. van Knijff-Raeven ${ }^{3}$, \\ H.M.J. van Schrojenstein Lantman-de Valk ${ }^{4}$, W.H.E. Buntinx ${ }^{5}$
}

Doel: Onderzoek naar de overeenstemming tussen gewichtsstatus classificaties (ondergewicht, normaal gewicht, overgewicht, ernstig overgewicht) op basis van vier antropometrische methoden: Body Mass Index (BMI), buikomvang, Vet Vrije Massa Index (VVMI) en huidplooimeting. Methoden: De onderzoeksgroep bestond uit 91 personen (27 mannen en 64 vrouwen) in de leeftijd van 18-63 jaar. Gewichtsstatus werd bepaald via BMI, buikomvang, VVMI en huidplooimeting afzonderlijk. Overeenstemming in classificatie op basis van de vier maten werd berekend door middel van Cohens kappa. Resultaten: De overeenstemmingen tussen de vier methoden ten aan zien van gewichtsstatus bleken laag. Dat gold ook ten aanzien van bijna alle overeenstemmingen in aparte analyses naar geslacht en leeftijd. Conclusie: Er is weinig overeenstemming tussen de vier methoden bij het classificeren van de onderzoekspersonen naar gewichtsstatus. Nader onderzoek naar de voordelen, nadelen en validiteit van de methoden is wenselijk.

Trefwoorden: gewichtsstatus, overeenstemming, antropometrische methoden

\section{INLEIDING}

Wereldwijd hebben een miljard volwassenen overgewicht, waarvan ten minste 300 miljoen lijden aan obesitas. ${ }^{1}$ In 2008 had $47 \%$ van de Nederlandse bevolking overgewicht, waarvan $11 \%$ ernstig overgewicht. Van de Nederlandse bevolking had $2 \%$ ondergewicht. $^{2}$

Verwacht wordt dat het percentage van volwassenen met overgewicht met 50\% zal toenemen in de komende 20 jaar. $^{3}$ Overgewicht is een bedreiging voor de gezondheid. Het kan leiden tot diverse chronische aandoeningen zoals diabetes mellitus type 2 , hart- en vaatziekten, diverse soorten kanker en aandoeningen aan galblaas, bewegingsstelsel en ademhalingsorganen. Ook als gevolg van ondergewicht kunnen diverse lichamelijke klachten ontstaan, zoals lage lichaamstemperatuur, hart- en vaataandoeningen (hartritmestoornissen, verlaagde bloeddruk), osteoporose, maag- en darmklachten. ${ }^{3}$

Uit bovenstaande blijkt dat over- en ondergewicht forse gezondheidsrisico's met zich kunnen meebrengen.

\footnotetext{
${ }^{1}$ Maastricht University

2 Stichting Pergamijn / Vakgroep Verpleging en Verzorging / Gouverneur Kremers Centrum, Maastricht University

3 Stichting Pergamijn, Echt

4 afdeling Eerstelijnsgeneeskunde, UMC St Radboud

5 Gouverneur Kremers Centrum, Maastricht University
}

Het is daarom belangrijk dat eenvoudig kan worden nagegaan of iemand gezond gewicht, danwel over- of ondergewicht heeft. Desgewenst kunnen vervolgens acties worden ondernomen om ongezond gewicht te veranderen in gezond gewicht. Veelal worden antropometrische indicatoren gebruikt om gewichtsstatus (ondergewicht, normaal gewicht, overgewicht, ernstig overgewicht) te bepalen. Het voordeel van deze methoden is dat ze universeel toepasbaar zijn, relatief goedkoop en weinig belastend voor de betrokken persoon. ${ }^{5}$ De meest gebruikte antropometrische indicatoren om gewichtsstatus te bepalen, zijn de Body Mass Index (BMI), de buikomvang, Vet Vrije Massa Index (VVMI) en de huidplooidikte. Uit enkele studies blijkt echter dat deze methoden weliswaar eenvoudig uit te voeren zijn, maar niet nauwkeurig genoeg zijn om de daadwerkelijke lichaamssamenstelling en dus gewichtsstatus te bepalen. ${ }^{5-7}$ De methoden suggereren weliswaar hetzelfde concept (gewichtsstatus) te meten, maar het is de vraag in hoeverre deze methoden onderling overeenstemmen. Tegenwoordig wordt veel aandacht in onder andere de media geschonken aan overgewicht en de risico's daarvan. Het gevolg is dat mensen inzicht willen hebben in hun gewichtsstatus en een of meerdere van deze eenvoudig uit te voeren methoden hiervoor gebruiken. De keuze voor welke me- 
thode is mede afhankelijk van de benodigde hulpmiddelen of kennis die iemand heeft ten aanzien van het bepalen van de gewichtsstatus. Vervolgens kan het van de gebruikte methode afhangen in welke gewichtsstatus een persoon wordt ingedeeld en of een persoon haar/zijn gewicht op grond van die indeling wenst te beïnvloeden. Zo kan het bijvoorbeeld voorkomen dat iemand zijn BMI en buikomtrek bepaalt. Hij concludeert dat hij ruim binnen de marges van gezond gewicht valt volgens de BMI, maar wel een te grote buikomvang heeft. Uit een meting van de huidplooidikte blijkt sprake te zijn van licht overgewicht. Of er op grond van deze drie uitslagen voor deze persoon vervolgacties (wel/niet minder eten en/of meer bewegen) nodig zijn, is dan voor hem onduidelijk.

De onderzoeksvraag is dus of deze methoden gelijke uitkomsten in gewichtsstatus classificatie geven bij dezelfde individuen. Indien de methoden gelijke uitkomsten geven, kan vervolgens de goedkoopste en/of minst belastende methode worden gekozen als hulpmiddel voor de bepaling van gewichtsstatus. Indien de methoden niet tot gelijke conclusies leiden, moet worden bepaald welke methode het meest valide is en/of moet worden bepaald wat de methoden afzonderlijk exact meten.

De overeenstemming tussen gewichtsstatus classificaties op basis van de vier genoemde antropometrische methoden (BMI, buikomvang, VVMI en huidplooidikte) is één keer eerder onderzocht. ${ }^{8}$ Uit dat onderzoek blijkt dat de onderlinge overeenstemming tussen de vier methoden laag was. Deze lage onderlinge overeenstemming is mogelijk te verklaren door het feit dat het onderzoek is uitgevoerd bij personen met een verstandelijke handicap. Deze antropometrische meetresultaten van personen met een verstandelijke handicap zijn echter niet zonder meer vergelijkbaar met die van personen zonder verstandelijke handicap, onder andere vanwege de vaak afwijkende posturen van eerstgenoemde groep, bijkomende lichamelijke handicaps en afwijkend metabolisme. Er zijn geen andere studies bekend waarin de overeenstemming tussen deze vier antropometrische meetmethoden is bepaald bij mensen zonder verstandelijke handicap. Vandaar dat dit onderzoek zich hierop richt.

De onderzoeksvraag luidt: Wat is de overeenstemming tussen classificaties in de gewichtsstatus (ondergewicht, normaal gewicht, overgewicht, ernstig overgewicht) op basis van BMI, buikomvang, Vet Vrije Massa Index en huidplooidikte?

\section{MATERIALEN EN METHODEN}

\section{Onderzoeksgroep}

Volwassen werknemers en vrijwilligers die werken bij een Nederlandse zorgaanbieder werden via intranet en e-mail opgeroepen deel te nemen aan het onderzoek. Omdat bekend is dat de vier methoden onvoldoende valide zijn voor kinderen, jongeren en senioren, en voor mensen met sterk afwijkende lichaamsposturen, ${ }^{8}$ moesten de deelnemers tussen 18 en 65 jaar oud zijn en geen extreem afwijkende lichaamssamenstelling, zoals dwerggroei of extreme obesitas, hebben.

Negenennegentig personen hebben zich aangemeld. Acht van hen zijn niet in de analyses betrokken. Bij vijf deelnemers zijn geen metingen verricht wegens ziekte, een personen is geëxcludeerd wegens falende bio-impedantiemeting, en twee personen zijn geëxcludeerd wegens extreme obesitas (BMI >34). Uiteindelijk dus zijn 91 personen in het onderzoek betrokken. Deze personen waren tussen 18 tot 63 jaar oud, er waren 27 mannen en 64 vrouwen (zie tabel 1).

\section{Metingen}

Gewichtsstatus werd vier keer door steeds dezelfde onderzoeker bepaald: via de BMI, de buikomvang, de Vet Vrije Massa Index en de huidplooimeting.

De BMI werd verkregen door het gewicht en lengte te meten. Gewicht werd gemeten tot 0,1 kilogram nauwkeurig en lengte werd per 0,5 centimeter gelezen. De BMI werd berekend via de formule: (lichaamsgewicht in $\mathrm{kg}$ ) / (lengte in meters $)^{2}$. Categorieën met bijbehorende afkappunten zijn: ondergewicht $\left(<18,5 \mathrm{~kg} / \mathrm{m}^{2}\right)$, normaal gewicht $\left(18,5<25 \mathrm{~kg} / \mathrm{m}^{2}\right)$, overgewicht $\left(25<30 \mathrm{~kg} / \mathrm{m}^{2}\right)$ en ernstig overgewicht $\left(\geq 30 \mathrm{~kg} / \mathrm{m}^{2}\right){ }^{1}$

De buikomvang werd verkregen door een meetlint om de buik te plaatsen, ter hoogte van de navel. De grootte van de buikomvang werd afgelezen tot 0,5 centimeter nauwkeurig. Categorieën en afkappunten voor de buikomvang zijn als volgt: ondergewicht en normaal gewicht $(<94 \mathrm{~cm}$ voor mannen en $<80 \mathrm{~cm}$ voor vrouwen), overgewicht $(94-102 \mathrm{~cm}$ voor mannen en $80-88 \mathrm{~cm}$ voor

Tabel 1 Onderzoekspersonen naar aantal, leeftijd, lengte en gewicht; totaal en naar geslacht

\begin{tabular}{llll}
\hline Kenmerken / Geslacht & Totaal & Man & Vrouw \\
\hline Aantal & 91 & 27 & 64 \\
Leeftijd in jaren (gemiddeld, range) & $42,2(18-63)$ & $42,8(18-63)$ & $41,9(18-60)$ \\
Lengte in meters (gemiddeld, range) & $1,71(1,54-1,94)$ & $1,79(1,65-1,94)$ & $1,68(1,54-1,85)$ \\
Gewicht in kg. (gemiddeld, range) & $71,5(49,6-110,0)$ & $80,3(58,0-110)$ & $67,8(49,6-104,5)$ \\
\hline
\end{tabular}


vrouwen) en ernstig overgewicht ( $>102 \mathrm{~cm}$ voor mannen en $>88 \mathrm{~cm}$ voor vrouwen). ${ }^{9}$

De derde methode, de huidplooimeting, werd uitgevoerd met een Harpenden huidplooimeter (Holtain Ltd. Carymmych, UK). Huidplooien werden gemeten op vijf plaatsen, te weten de biceps, triceps, subscapular, suprailliac en het bovenbeen. Deze dikten van de huidplooien werden afgelezen tot de millimeter nauwkeurig. Om de percentages lichaamsvet te berekenen is gebruikt gemaakt van de formule van Durnin en Womersley voor mannen. ${ }^{10,11}$

$C-M^{*} \log$ (som van de huidplooi van de biceps, triceps, subscapular en suprailliac).

Voor vrouwen is gebruik gemaakt van de formule van Jackson. $^{12}$

$B D=1,0994921-0,0009929^{*}$ (som van de huidplooi van de triceps, bovenbeen en suprailliac) $+0,0000023^{*}$ (som van de triceps, bovenbeen en suprailliac) ${ }^{2}-$ 0,0001392* (leeftijd). Beide formules berekenen de lichaamsdichtheid. Om het percentage lichaamsvet te verkrijgen moeten de uitkomsten ingevoerd worden in de volgende formule:

$\%$ lichaamsvet $=[(4,95 /$ lichaamsdichtheid $)-$ $4,5]^{*} 100 \%$. $^{13}$

De onderzoekspersonen zijn op grond van de uitslagen van de meting ingedeeld in de bijbehorende gewichtsklasse: ondergewicht ( $<15 \%$ voor mannen en $<18 \%$ voor vrouwen), normaal gewicht $(15-<22 \%$ voor mannen en $18-<32 \%$ voor vrouwen), overgewicht $(22-<25 \%$ voor mannen en $32-<35 \%$ voor vrouwen) en ernstig overgewicht ( $\geq 25 \%$ voor mannen en $\geq 35 \%$ voor vrouwen). ${ }^{14}$

De Vet Vrije Massa Index (VVMI) is gemeten via de Hydra 4200 bio-impedantiemeter (Xitron Technologies, San Diego, CA, USA). Hieruit werd de Vet Vrije Massa (VVM) verkregen. Door de VVM te delen door de lengte $^{2}$, is de VVMI verkregen (VVM/lengte ${ }^{2}$ ). De gebruikte afkappunten zijn ondergewicht $\left(<16,8 \mathrm{~kg} / \mathrm{m}^{2}\right.$ voor mannen en $<14,9 \mathrm{~kg} / \mathrm{m}^{2}$ voor vrouwen), normaal gewicht $\left(16,8-19,6 \mathrm{~kg} / \mathrm{m}^{2}\right.$ voor mannen en $14,9-16,6 \mathrm{~kg} /$ $\mathrm{m}^{2}$ voor vrouwen), en overgewicht en ernstig overgewicht $\left(>19,6 \mathrm{~kg} / \mathrm{m}^{2}\right.$ voor mannen en $>16,6 \mathrm{~kg} / \mathrm{m}^{2}$ voor vrouwen). ${ }^{14}$

\section{Data analyse}

Statistische analyses zijn uitgevoerd met behulp van het programma SPSS 15.0. Eerst zijn de frequenties van de gewichtsstatus volgens de vier meetmethoden berekend.

Voor het bepalen van de mate van overeenstemming tussen classificaties in gewichtsstatus is gebruikgemaakt van Cohens kappa. Deze geeft de mate van overeenstemming tussen categorische data aan, waarbij steeds wordt gecorrigeerd voor toevalsovereenstemming. De waarde +1 duidt op een perfecte positieve overeenstemming; de waarde -1 op een perfecte negatieve overeenstemming (de ene waarneming geeft precies het tegenovergestelde aan van de andere waarneming). Als de waarde van kappa 0 is, geeft dit aan dat er slechts sprake is van toevalsovereenstemming. Er kan van een acceptabele positieve overeenstemming worden gesproken als de kappawaarde groter is dan $0,6{ }^{15,16}$

\section{RESULTATEN}

Tabel 2 laat zien dat de VVMI van de vier methoden met $28 \%$ het minst aantal personen met overgewicht of ernstig overgewicht (obesitas) classificeert. Bij de BMI, buikomvang methode en huidplooimeting is dit respectievelijk 37\%, 64\% en 41\%. Volgens de VVMI heeft ruim een kwart van de onderzoeksgroep ondergewicht. Bij de BMI is dit $0 \%$ en bij de huidplooimeting $4 \%$.

Berekeningen van Cohens kappa wijzen uit dat er onvoldoende overeenstemming is tussen de vier meetmethoden (tabel 3). De minst slechte overeenstemming (kappa: 0,30) werd gevonden tussen BMI en huidplooidikte. De andere vergelijkingen resulteerden in nog lagere kappawaarden. Omdat alle methoden behalve BMI aparte afkappunten hebben voor mannen en vrouwen, is Cohens kappa tevens berekend voor mannen en vrouwen afzonderlijk. Tabel 4 laat zien dat de overeenstemming bij mannen tussen buikomvang en hoeveelheid vetvrije massa goed (kappa $=0,77)$ is. De overige vergelijkingen leverden lage overeenstemmingen tussen de classificaties van de vier methoden op (kappa $<0,4)$. Het percentage lichaamsvet en de samenstelling van het lichaam verandert bij veroudering en daarom is bij ouderen een afname in vet vrije massa te verwachten. ${ }^{7}$ Omdat ook dit de resultaten kan beïnvloeden, is tevens een berekening van kappawaarden uitgevoerd voor personen onder de 40 en personen boven de 40 jaar afzonderlijk (zie tabel 5). Ook hier blijkt dat de afzonderlijke berekeningen per leeftijdsgroep leiden tot geringe overeenstemming (kappa $<0,3)$.

\section{DISCUSSIE}

Uit de resultaten blijkt dat overeenstemming tussen classificatie in gewichtsstatus op basis van de vier antropometrische methoden BMI, buikomvang, VVMI en huidplooimeting, laag is. De hoogste overeenstemming in de totale studiepopulatie werd gevonden tussen BMI en huidplooidikte (kappa: 0.30). De enige goede overeenstemming werd gevonden tussen de buikomvang en hoeveelheid vetvrije massa bij mannen. Opgemerkt moet daarbij worden dat deze vergelijking is gebaseerd op een tweedeling in ondergewicht en gezond gewicht enerzijds en overgewicht en ernstig overgewicht anderzijds. Er is

Tabel 2 Verdeling van de gewichtsstatusuitkomsten naar meetmethode, procentueel en (absoluut)

\begin{tabular}{lccc}
\hline Gewichtstatus uitkomst & Body Mass Index & $\begin{array}{c}\text { Meetmethode } \\
\text { Buikomvang }\end{array}$ & Vet Vrije Massa Index \\
\hline Ondergewicht & $0 \%(0)$ & $36 \%(33)$ & $28 \%(25)$ \\
Normaal gewicht & $63 \%(57)$ & $4 \%(4)$ & $44 \%(41)$ \\
Overgewicht & $33 \%(30)$ & $35 \%(32)$ & $25 \%(50)$ \\
Ernstig overgewicht (obesitas) & $4 \%(4)$ & $29 \%(26)$ & $13 \%(12)$ \\
\hline
\end{tabular}


Tabel 3 Overeenstemming tussen de vier meetmethoden in de totale onderzoeksgroep

\begin{tabular}{llll}
\hline Meetmethoden & N & Gewichtscategorieën & Kappa met 95\% betrouwbaarheidsinterval \\
\hline $\mathrm{BMI}^{1}$ vs. $\mathrm{BO}^{2}$ & 91 & $\left(\mathrm{O}^{5}+\mathrm{N}^{6}\right)$ vs. $\left(\mathrm{Ov}^{7}\right)$ vs. $\left(\mathrm{Ob}^{8}\right)$ & $0,13(-0,05-0,31)$ \\
$\mathrm{BMI}$ vs. VVMI & 91 & $(\mathrm{O}+\mathrm{N})$ vs. $(\mathrm{Ov}+\mathrm{Ob})$ & $0,23(0,06-0,41)$ \\
$\mathrm{BMI}$ vs. HM & 91 & $(\mathrm{O})$ vs.(N) vs.(Ov) vs.(Ob) & $0,30(0,16-0,45)$ \\
$\mathrm{BO}$ vs. VVMI & 91 & $(\mathrm{O}+\mathrm{N})$ vs.(Ob $+\mathrm{Ov})$ & $0,20(-0,06-0,46)$ \\
$\mathrm{BO}$ vs. HM & 91 & $(\mathrm{O}+\mathrm{N})$ vs.(Ov $+\mathrm{Ob})$ & $0,18(0,01-0,36)$ \\
VVMI vs. HM & 91 & $(0)$ vs.(N) vs.(Ov + Ob) & $0,09(-0,08-0,27)$ \\
\hline
\end{tabular}

${ }^{1}$ BMI : Body Mass Index

2 BO: Buikomvang

${ }^{3}$ VVMI: Vet Vrije Massa Index

4 HM: Huidplooimeting

${ }^{5}$ O: Ondergewicht

${ }^{6} \mathrm{~N}$ : Normaal gewicht

${ }^{7}$ Ov: Overgewicht

${ }^{8}$ Ob: Obesitas

Tabel 4 Overeenstemming tussen de vier meetmethoden naar geslach

\begin{tabular}{llll}
\hline Meetmethoden & Gewichtscategorieën & $\begin{array}{l}\text { Kappa met 95\% betrouwbaarheids- } \\
\text { interval 'man' (n=27) }\end{array}$ & $\begin{array}{l}\text { Kappa met 95\% betrouwbaarheids- } \\
\text { interval 'vrouw' (n=64) }\end{array}$ \\
\hline BMI vs. BO & $(\mathrm{O}+\mathrm{N})$ vs.(Ov) vs.(Ob) & $0,37(0,05-0,68)$ & $0,10(-0,15-0,35)$ \\
BMI vs. VVMI & $(\mathrm{O}+\mathrm{N})$ vs.(Ov) vs.(Ob) & $0,21(-0,09-0,52)$ & $0,23(0,01-0,45)$ \\
BMI vs. HM & $(\mathrm{O})$ vs.(N) vs.(Ov)vs(Ob) & $0,21(-0,09-0,51)$ & $0,31(0,12-0,50)$ \\
BO vs. VVMI & $(\mathrm{O}+\mathrm{N})$ vs.(Ob + Ov) & $0,77(0,53-1,00)$ & $0,14(-0,23-0,50)$ \\
BO vs. HM & $(\mathrm{O}+\mathrm{N})$ vs.(Ov vs.Ob) & $0,30(-0,01-0,61)$ & $0,23(0,00-0,46)$ \\
VVMI vs. HM & $(\mathrm{O})$ vs.(N) vs.(Ov + Ob) & $0,15(-0,22-0,51)$ & $0,05(0,00-0,29)$ \\
\hline
\end{tabular}

Tabel 5 Overeenstemming tussen de vier meetmethoden per leeftijdsgroep

\begin{tabular}{|c|c|c|c|}
\hline Meetmethoden & Gewichtscategorieën & $\begin{array}{l}\text { Kappa met } 95 \% \text { betrouwbaarheids- } \\
\text { interval }(\dot{\cdots} \cdot \cdots 0 \text { jaar; } n=35)\end{array}$ & $\begin{array}{l}\text { Kappa met } 95 \% \text { betrouwbaarheids- } \\
\text { interval }(\geq 40 \text { jaar; } n=56)\end{array}$ \\
\hline BMI vs. BO & $(\mathrm{O}+\mathrm{N})$ vs.(Ov) vs.(Ob) & $0,14(-0,17-0,45)$ & $0,11(-0,12-0,34)$ \\
\hline BMI vs. VVMI & $(\mathrm{O}+\mathrm{N})$ vs. $(\mathrm{Ov})$ vs. $(\mathrm{Ob})$ & $0,14(-0,19-0,46)$ & $0,29(0,08-0,50)$ \\
\hline BMI vs. HM & (O) vs.(N) vs.(Ov)vs(Ob) & $0,29(0,01-0,58)$ & $0,30(0,11-0,48)$ \\
\hline BO vs. VVMI & $(\mathrm{O}+\mathrm{N})$ vs. $(\mathrm{Ob}+\mathrm{Ov})$ & $0,07(-0,38-0,52)$ & $0,26(-0,06-0,57)$ \\
\hline BO vs. HM & $(\mathrm{O}+\mathrm{N})$ vs. $(\mathrm{Ov}$ vs. $\mathrm{Ob})$ & $0,26(-0,05-0,57)$ & $0,10(-0,12-0,31)$ \\
\hline VVMI vs. HM & (O) vs. $(\mathrm{N})$ vs. $(\mathrm{Ov}+\mathrm{Ob})$ & $-0,03(-0,34-0,28)$ & $0,16(-0,05-0,38)$ \\
\hline
\end{tabular}

dus sprake van clustering in gewichtsstatus en daardoor mogelijk grotere kans op betere overeenstemming. Dat de kappawaarden bij de andere vergelijkingen desondanks laag zijn, accentueert de uitkomst van geringe overeenstemmingen.

Er zijn diverse beperkingen van de methoden te noemen. Enerzijds betreft dat de manier van meten met mogelijke consequenties voor de nauwkeurigheid van de uitkomsten. Anderzijds betreft het de aanschaf en beschikbaarheid van de benodigde instrumentaria.

De BMI wordt veel gebruikt en is internationaal erkend als een voldoende valide globale maat om obesitas vast te stellen. ${ }^{17}$ De BMI is namelijk gemakkelijk te meten en er is klein risico op onnauwkeurigheden bij de metingen van lengte en gewicht. ${ }^{18}$ De BMI heeft echter, zoals ook in de inleiding is aangegeven, ook nadelen. Er wordt namelijk alleen gerekend met de lengte en het gewicht van een persoon, maar niet met de daadwerkelijke lichaamssamenstelling (verhoudingen tussen spieren, botten en vetweefsel). ${ }^{19,20}$

Omdat abdominaal vet een indicator is voor een vergroot risico op hart en vaatziekten, ${ }^{21,22}$ is ook het meten van de buikomvang een vaak gebruikte methode. Het meten van de buikomvang vergt bovendien weinig training en is gemakkelijk uit te voeren. ${ }^{23-25}$ Het blijkt echter moeilijk de metingen aan de buik betrouwbaar uit te voeren omdat de plaats waar gemeten moet worden specifiek is. ${ }^{26}$ Het verkeerd plaatsen van het meetlint heeft effect op de uitkomst. ${ }^{27}$ Bovendien wordt bij het bepalen van de gewichtsstatus gemeten via de buikomvang geen rekening gehouden met leeftijd en lengte van de te meten persoon.

De huidplooimeting is nauwkeurig en de bijbehorende formules zijn valide om het percentage lichaamsvet te berekenen. Belangrijk hierbij is dat verschillende formules bestaan voor mannen en vrouwen, en dat tevens rekening wordt gehouden met leeftijd. ${ }^{12}$ Het is echter moeilijk om de huid goed vast te pakken, vooral bij personen met overgewicht. Bovendien is het moeilijk de precieze plaatsen voor de metingen te bepalen. Het nauwkeurig uitvoeren van de huidplooimeting vergt veel oefening en meetfouten zijn dan ook gemakkelijk te maken. $^{26,28}$

Ook het meten van de Vet Vrije Massa door middel van de bio-impedantiemeter gaat eenvoudig, snel en reproduceerbaar. ${ }^{7}$ De aanschaf van de meter is echter beduidend kostbaarder dan de instrumentaria voor de andere methodes en zo'n meter is niet voor iedereen zonder meer beschikbaar. Er is een minimale meetfout onder meters. ${ }^{29}$ Het verkeerd plaatsen van elektrodes kan niettemin tot grote meetfouten leiden. ${ }^{30}$ Verder wordt bij personen met overgewicht of obesitas de vergrote extra- 
cellulaire ruimte in hun vetweefsel door de bio-impedantiemeter geïnterpreteerd als een hogere vet vrije massa. ${ }^{31}$

De resultaten van dit onderzoek wijzen uit dat er weinig overeenstemming is tussen de uitkomsten ten aanzien van classificatie in gewichtsklasse via de methoden. Het is niet uitgesloten dat er onnauwkeurigheden zijn in de metingen. Er zijn echter geen test-hertest metingen gedaan om dit te kwantificeren.

De onderzoekspersonen zijn gerekruteerd onder personeel van één zorginstelling. Er was geen sprake van een aselecte steekproef. Dit is voor dit onderzoek echter geen noodzaak. Er is namelijk onderzocht in hoeverre bij deze personen sprake is van overeenstemming tussen vier methoden voor de bepaling van de gewichtsstatus. Het ligt wel voor de hand dat mensen met fors ongezond gewicht of ervaren ongezond gewicht minder snel aan dergelijk onderzoek zullen meedoen, omdat de resultaten confronterend kunnen zijn. Het aandeel van mensen met dergelijk gewicht zal in het onderzoek dan ook naar verwachting ondervertegenwoordigd zijn. Maar dat zal de resultaten ten aanzien van de intertest betrouwbaarheid niet wezenlijk hebben beïnvloed.

De resultaten komen overeen met het eerder genoemde onderzoek bij mensen met een verstandelijke handicap.$^{8}$ De overeenstemming in indeling in classificaties van gewichtsstatus via de vier methoden is ook in dit onderzoek laag. De uitkomst in welke gewichtsklasse men wordt ingedeeld en of men gezond danwel ongezond gewicht heeft kan dus verschillen tussen de vier methoden. Veel personen zullen inzicht willen hebben in hun gewichtsstatus. Dat zal dus snel, simpel en nauwkeurig gedaan moeten kunnen worden. De beschikbare gouden standaarden (bijvoorbeeld onderwaterweging, air-displacement plethysmography, DEXA) zijn kostbaar en relatief belastend en zijn dus ook niet zomaar beschikbaar.

Als, zoals uit dit onderzoek blijkt, het bepalen van de gewichtsstatus via diverse methoden verschillende resultaten oplevert, dan heeft opsporings- en behandelbeleid onvoldoende solide basis.

Via dit onderzoek kan niet worden aangegeven welke methode het meest valide is. Het meest aangewezen onderzoek hiervoor is longitudinaal onderzoek waarin voor de verschillende categorieën van gewichtsstatus de kans op diverse ziekten, beperkingen of vroegtijdig overlijden bepaald wordt. Bij de diverse manieren om de gewichtsstatus te bepalen zou dan ook een gouden standaard (bijvoorbeeld onderwaterweging, air-displacement plethysmography, DEXA) gebruikt moeten worden.

\section{ABSTRACT \\ Congruence among anthropometric indicators identifying the weight status}

Objective: To examine the congruence in weight status classification according to four anthropometric weight status methods: Body Mass Index (BMI), waist circumference, Fat Free Mass Index (FFMI) and skin fold thickness. Methods: The study sample consisted of 91 adult subjects. Weight status of all subjects was determined in terms of 'underweight', 'normal weight', 'overweight' and 'obese' on the basis of each of four anthropometric methods (BMI, waist circumference, FFMI and skin fold thickness). Congruence between classifications was calculated using Cohen's kappa. Results: The results of the study show different percentages per weight category when measured by the four anthropometric methods. All intertest agreements proved to be low in the total study group. This also counted for almost all agreements in separate analyses for gender and age. Conclusion: Outcomes of the four methods hardly agree with respect to classifying the study population in weight status. Further research into the strengths, weaknesses and validity of the methods is needed.

Keywords: weight status, congruence, anthropometric indicators

\section{LITERATUUR}

1. World Health Organization. Obesity and overweight. Geneva: WHO, 2008. http://www.who.int/dietphysicalactivity/publications/facts/obesity/en/ [updated 2009; cited 2009 March 19].

2. Centraal Bureau voor de Statistiek, Zelfgerapporteerde medische consumptie, gezondheid en leefstijl. http://statline.cbs.nl/ StatWeb/publication/?DM=SLNL\&PA=03799\&D1=267271\&D2=0-17\&D3=0\&D4=a\&VW=T [updated 2009 March 17; cited 2009 March 19].

3. RIVM. Lichaamsgewicht - de determinant, gezondheidsgevolgen en oorzaken. http://www.rivm.nl/vtv/object_document/ o1252n18950.html [updated 2008 December 18; cited 2009 March 19].

4. World Health Organization. Physical status: the use and interpretation of anthropometry. WHO technical report series, 854 . Geneva: WHO; 1995.

5. Pichard C, Kyle U, Bracco D, Slosman D, Morabia A. \& Schutz, $Y$. Reference calues of fat-free and fat masses by bioelectrical impedance analysis in 3393 healthy subjects. Nutrition 2000; 16:245-54.

6. Visscher T, Seidell J, Molarius A, Van der Kuip D, Hofman A, Witteman J. A comparison of body mass index, waist-hip ratio and waist circumference as predictors of all-cause mortality among the elderly: the Rotterdam study. Int J Obesity 2001;25: 1730-5.

7. Kyle U, Genton L, Karsegard L, Slosman D, Pichard C. Single prediction equation for bioeletrical impedance analysis in adults aged 20-94 years. Nutrition 2001;17:248-53.

8. Verstraelen CJF, Maaskant MA, Knijff-Raeven AGM van, Curfs LMG, Schrojenstein Lantman - de Valk HMJ van. Weighting the weights: agreement among anthropometric indicators identifying the weight status of people with intellectual disabilities. J Appl Res Intellectual Disabilities 2009;22:307-13.

9. Lean M, Han T, Morrison C. Waist circumference as a measure for indicating need for weight management. Br Med J 1995; 311:158-61.

10. Rimmer J, Kelly L. Accuracy of anthropometric equations for estimating body composition of mentally retarded adults. Am J Ment Def 1987;91:626-32.

11. Durnin J, Womersley J. Body fat assessed from total body density and its estimation from skinfold thickness: measurements on 481 men and women aged from 16 to 72 years. Br J Nutr 1974;32:77-97.

12. Jackson A, Pollock M, Ward A. Generalized equations for pre- 
dicting body density of women. Med Science Sports Exercise 1980;12:175-82.

13. Siri W, Lawrence J, Tobias C. Gross composition of the body. Adv Biol Med Physics 1956;4:239-80.

14. Pi-Sunyer FX. Obesity: criteria and classification. Proc Nutrition Society 2000;59:505-9.

15. Landis J, Koch $G$. The measurement of observer agreement for categorical data. Biometrics 1977;33:159-74.

16. Yperen $T$ van. Multi-axale clasificatie van specifieke ontwikkelingsstoornissen. Een studie over het as II van het MAC. Leiden: Leiden University, 1990.

17. Food and Agricultue Organization of the United Nations. BMI as a reflection of the body energy stores. http://www.fao.org/ docrep/t1970e/t1970e03.htm [updated 1994; cited 2009 March 19].

18. Ulijaszek S, Kerr D. Antropometric measurement error and the assessment of nutritional status. Br J Nutrition 1999;82:165-77.

19. Bagust A, Walley T. An alternative to body mass index for standardizing body weight for stature. Quart J Medicine 2000; 93:589-6.

20. Schultz Y, Kyle U, Pichard C. Fat-free mass index and fat mass index percentiles in Caucasians aged 18-98y. Int J Obes Relat Metab Disord. 2002;26:953-60.

21. Han T, Seidell J. Curral J, Morrison C, Deurenber P, Lean M. The influences of height and age on waist circumference as an index of adiposity in adults. Int J Obesity 1997;21:83-9.

22. Janssen I, Katzmarzyk P, Ross R. Body mass index, waist circumference, and health risk: evidence in support of current National Institutes of Health guidelines. Arch Intern Med. 2002;62:2074-9.

23. Lean $M$, Han T, Deurenberg P. Predicting body composition by densitometry from simple anthropometric measurement. Am J Clin Nutrition 1996;63:4-14
24. Lean M, Han T. Waist worries. Am J Clin Nutrition 2002;76: 699-700.

25. Nádas J, Putz Z, Kolev G, Nagy S, Jermendy G. Intraobserver and interobeserver variability of measuring waist circumference. Med Science Monitor 2008;14(1):CR15-18.

26. Moreno L, Joyanes M, Mesana $M$ et al. Harmonization of anthropometric measurements for a multicenter nutrition survey in Spanish adolescents. Nutrition 2003;19:481-6.

27. Wang J, Thornton J, Bari S et al. Comparisons of waist circumferences measured at 4 sites. Am J Clin Nutrition 2003;77, 379-84.

28. Steward S, Bramley P, Heighton R et al. Estimation of body composition from bioelectrical impedance of body segments: comparison with dual-energy X-ray absorptiometry. Br J Nutrition 1993;69:645-55.

29. Jackon A, Pollock M, Graves J, Mahar M. Reliability and validity of bioeletrical impedance in determining body composition. J Appli Physiol 1988;64:529-34.

30. Bray $G$. Determining body composition in adults. http:// www.uptodate.com/patients/content/topic.do?topicKey=obesity/7584 [updated 2008 October; cited 2009 March 19].

31. Williams $C$, Bale P. Bias and limits of agreement between hydrodensitometry, bioelectrical impedance and skinfold capilers measures of percentage body fat. Eur J Appl Physiol1998;77:271-7.

\section{CORRESPONDENTIEADRES}

Marian Maaskant, Stichting Pergamijn, Postbus 40,

NL-6100 AA Echt, tel. 0475-479535,

e-mail: m.maaskant@pergamijn.org

Voor publicatie aanvaard in maart 2010. 